\title{
ELEODORO VARGAS VICUÑA “EL TROVADOR DE LOS ANDES”. OBRA POÉTICA, NARRATIVA Y VIDA (2019).
}

Reinhard Seifert. Lima, edición del autor.

doi: https://doi.org/10.26439/en.lineas.generales2020.n3-4.5094

\author{
Paolo de Lima \\ Universidad de Lima
}

Reinhard Seifert, ingeniero civil y economista agrario, nació en Alemania en 1952 y reside en el Perú desde la edad de 25 años, exactamente desde el año 1977. En Cajamarca, se desempeña como ambientalista, así como promotor (a través de la actividad periodística y la investigación) de la economía de corte campesino y su cultura. El libro que ahora nos ocupa está dedicado al estudio y difusión de la obra del destacado escritor de la generación del 50 Eleodoro Vargas Vicuña (Cerro de Pasco, 1924 - Lima, 1997), célebre por sus libros de cuentos Nahuín (1953) y Taita Cristo (1964), de carácter lírico y vertiente neoindigenista.

Seifert estructura su libro Eleodoro Vargas Vicuña "El trovador de los Andes". Obra poética, narrativa y vida a través de doce capítulos cortos y secuenciales, al modo de una biografía: “Sus primeros pasos" (pp. 15-22), “Su vocación y su talento" (pp. 23-40), “Su relación amical con Rulfo" (pp. 41-44), "Su poesía” (pp. 45-50), “Su habla” (pp. 51-60), “Sus personajes" (pp. 61-62), “Sus años vividos" (pp. 63-66), “Su muerte” (pp. 67-68), “Su no indigenismo" (pp. 69-72), "Sus influencias" (pp. 73-76), "Sus obras” (pp. 77-78) y “Mi crítica" (pp. 79-84). El autor hilvana su discurso con una serie de comentarios críticos que la obra de Vargas Vicuña ha venido suscitando a lo largo de los años. Complementa a su vez su libro con un nutrido "Registro fotográfico" (pp. 89-98) y una serie de anexos: una entrevista ofrecida por EVV dos meses antes de su deceso, un "Retrato de poeta", una carta, una presentación al catálogo de un pintor, su intervención en un encuentro de escritores en Trujillo en 1986, una selección de sus cuentos más célebres ("Esa vez del huaico", “El tuco y la paloma”, “La Pascualina”, “Tata Mayo") y la inclusión íntegra de su poemario Zora, imagen de poesía (Ediciones de la Rama Florida, 1964), con el que ganara en 1959 el Concurso de Fomento a la Cultura "José Santos Chocano".

Vargas Vicuña vivió sus primeros años en un pueblo rural, Acobamba, ubicado en la provincia de Tarma, en el departamento de Junín, donde estudió la educación primaria entre 1931 y 1936 (cursó los años de secundaria entre 1937 y 1941 en Lima en el colegio nacional Nuestra Señora de Guadalupe). Nahuín precisamente basa su escritura en el habla y cosmovisión de la gente de dicho pueblo (p. 15), y el escritor "con el uso ascético, austero o frugal, en el uso de la palabra escrita, da un homenaje al hombre del campo" 
(p. 30) desde una perspectiva en la que la muerte está muy presente (p. 25). Concretamente, tanto a él como al escritor mexicano Juan Rulfo les "encantaban las visitas a los cementerios" (p. 41).

Quienes conocen la obra de Vargas Vicuña seguramente han oído hablar de la relación que suele establecerse entre su estilo narrativo y el de Juan Rulfo. Tanto Ñahuín como El llano en llamas, el célebre libro de cuentos de Rulfo, se publican en 1953, si bien el libro de Vargas Vicuña aparece unos meses antes. Seifert sostiene:

\begin{abstract}
Hay evidencias testimoniales que indican que EVV escribió sus cuentos sin conocer los textos del mexicano. Sin duda alguna, EVV se refería a Rulfo como a un hermano y Rulfo a él, del mismo modo, con mucho respeto y cariño. Es más, Rulfo -en una carta dirigida al escritor peruano- le comenta que ambos han hecho lo mismo en sus respectivos países: recuperar la voz del pueblo y hacerla universal. Fueron diestros en el manejo del lenguaje de sus pueblos. Luego ambos fueron compadres. Cada uno por su lado estuvo escrudiñando la psiquis de la gente y así producir sus obras literarias. (pp. 41-42)
\end{abstract}

De hecho, como el propio Vargas Vicuña ha testimoniado, fue Rulfo quien lo invitó a un congreso latinoamericano de escritores celebrado en México en 1965, donde participó junto al cubano Alejo Carpentier, el guatemalteco Miguel Ángel Asturias, el mexicano Octavio Paz y el colombiano Gabriel García Márquez.

Vale la pena destacar que la visión crítica de Reinhard Seifert respecto a la obra de Eleodoro Vargas Vicuña señala que el hilo conductor de sus cuentos es:

encontrar el significado histórico, psicológico y hasta religioso de la palabra morir. Alrededor de esta palabra se describe y se desarrolla la historia de sus cuentos. En algunos casos más que otros. Pero siempre hay una alusión explícita a esta palabra. Indudablemente. En algún párrafo aparece, él describe siempre algo al respecto y todo relacionado con la muerte, algo que trasciende, a veces con más empeño y profundidad; quiere decir, la palabra matar, morir, muerte, muerto, cementerio, nicho, agonía, velorio o alma está vigente. (p. 79)

Es meritoria esta reivindicación realizada por Reinhard Seifert sobre la vida y obra de Vargas Vicuña, considerado por el novelista Miguel Gutiérrez en su importante estudio La generación del 50: un mundo dividido (1988) como "uno de los mayores artífices de la lengua de la narrativa peruana" (p. 106). Una opinión muy similar la tuvo el escritor Oswaldo Reynoso, por ejemplo, en las declaraciones que me brindó en el velatorio de Vargas Vicuña realizado en el Museo de la Nación para la nota necrológica que publiqué en el desaparecido diario El Sol de Lima.

Quiero terminar esta reseña del libro de Reinhard Seifert con la célebre frase que Vargas Vicuña repitió una y otra vez en el legendario bar Palermo del Centro de Lima: "¡Viva la vida!". 